\title{
A Statewide Survey of the Beliefs and Practices of Chapter 1 Reading Teachers
}

JAMES A. MUCHMORE
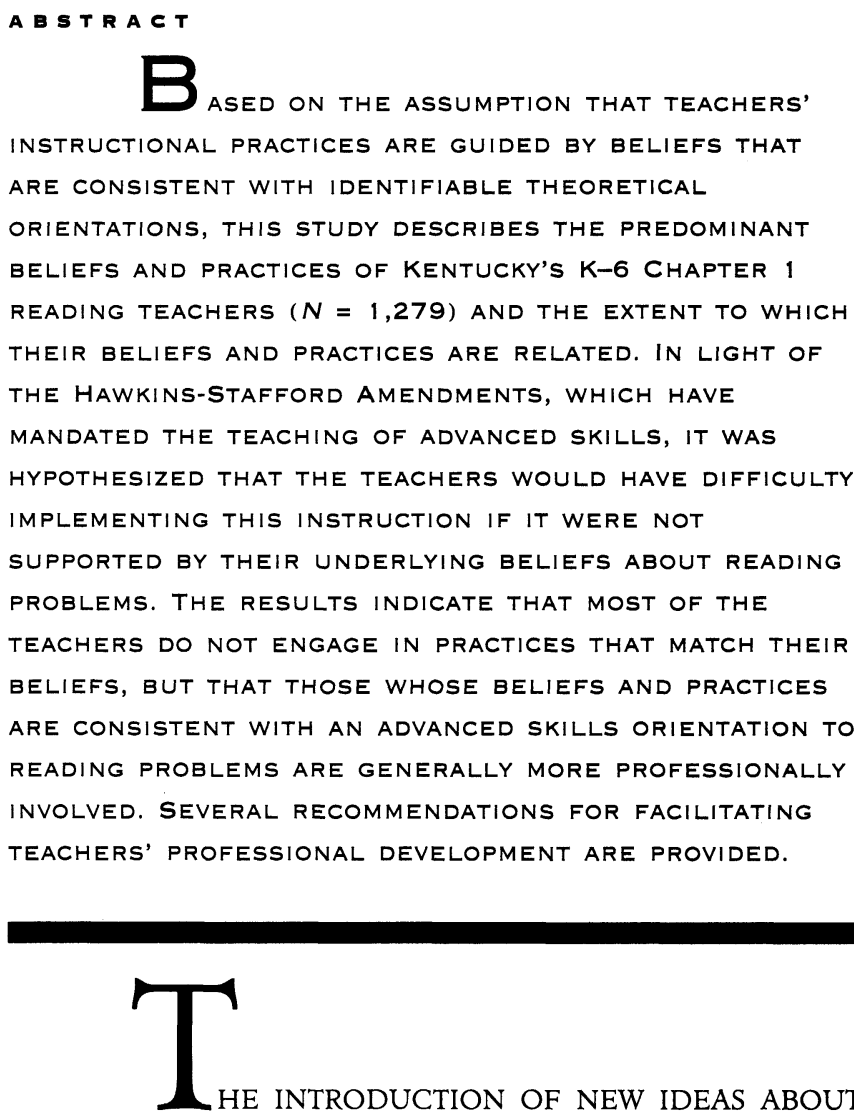
literacy and literacy instruction through reform movements has created unique opportunities for examining the relationship between teachers' beliefs and practices. For example, Chapter 1 instruction-both reading and mathhas traditionally been closely linked to the idea of skills remediation, as teachers have systematically tested children for specific deficiencies, taught the skills in which they were deficient, and then retested for mastery (Knapp, Shields, \& Turnbull, 1992; U.S. Department of Education, 1992). Recently, however, this type of instruction has received a great deal of criticism for focusing too much on basic skillsdecoding in reading and computation in math-while ignoring more advanced skills such as comprehension strategies and problem solving (e.g., Calfee, 1986; Romberg, 1986; Zumwalt, 1986). Indeed, Romberg has characterized Chapter 1 instruction as "defined by the workbooks and judged by the tests" (p. IV-15), while Knapp, Turnbull, and Shields (1986) have suggested that this kind of curriculum "lacks both coherence and intellectual challenge for the students who experience it" (p. 4).

Through the Hawkins-Stafford Amendments of 1988, policymakers sought to address such criticisms by explicitly requiring that instruction in advanced skills-reasoning, analysis, problem solving, interpretation, and decision making-be included in all Chapter 1 programs. Consequently, the law currently states that the purpose of Chapter 1 is to "improve the educational opportunities of educationally deprived children by helping them to succeed in the regular program, attain grade-level proficiency, and improve achievement in basic and more advanced skills [italics added]" (U.S. Department of Education, 1990, p. i). In the area of reading, advanced skills are synonymous with comprehension strategies, such as the setting of goals, the activation of background knowledge, and the monitoring of one's understanding.

Although changing the law is an important first step in improving teachers' practices, research has shown that teachers may have difficulty in implementing new classroom practices when the implicit assumptions of these practices do not match their existing beliefs (e.g., Hollingsworth, 1989; Munby, 1984; Richardson, 1990). For example, Clark 
and Peterson (1986) have stated that "a teacher's cognitive and other behaviors are guided by and make sense in relation to a personally held system of beliefs, values and principles" (p. 237), while researchers such as Rupley and Logan (1986); Kinzer and Carrick (1986); Richardson, Anders, Tidwell, and Lloyd (1991); and Johnson (1992) have shown that the instructional practices of reading teachers are directly related to their underlying beliefs about reading. These findings suggest that in Chapter 1, those teachers who believe that reading problems are related to basic skill deficiencies would be apt to teach lessons that focus heavily on basic skills, while those who associate reading problems with the inappropriate use of strategies would be more likely to see the need to teach lessons that focus on advanced skills. Thus, since Chapter 1 teachers have traditionally placed a heavy emphasis on basic skills and mastery learning, it is quite possible that these practices are still deeply embedded in current Chapter 1 instruction-in spite of concerted efforts to disseminate knowledge to teachers about advanced skills (e.g., Advanced Technology, 1990).

Currently, the extent to which Chapter 1 teachers actually integrate advanced skills into their instructional practices remains unclear. For example, an ERIC search revealed no studies that investigate the prevalence of advanced skills instruction in compensatory reading classrooms or explore the extent to which Chapter 1 teachers may possess a strategies orientation to reading problems. Therefore, the purpose of this study is to determine the predominant beliefs and practices of Chapter 1 reading teachers and the extent to which these beliefs and practices are related. In addition, it seeks to identify the professional characteristics of those teachers with matching beliefs and practices in the hope that this information can help to inform future efforts in professional development.

\section{METHOD}

\section{Four Theoretical Orientations to Reading Problems}

Although the issue that motivated this study dealt primarily with two orientations to reading problems-skills and strategies-it was recognized that such a simple dichotomy failed to account for the total range of possible orientations that compensatory reading teachers may possess. According to Wixson and Lipson (1991), reading problems have historically been studied from a variety of perspectives, and their indepth review of the literature provided a good starting point for thinking about the various theoretical orientations that may currently underlie the beliefs and practices of Chapter 1 reading teachers. Specifically, Wixson and Lipson have identified five perspectives that have guided the research: medical, psychoeducational, information processing, social, and interactive.
The medical perspective assumes that reading problems are rooted in neurological sources, commonly referred to as minimal brain dysfunction, developmental lag, pathological brain-behavior relations, or any number of similar terms. Somewhat related, but not limiting the etiology of reading problems to neurological malfunctions, is the psychoeducational perspective, which recognizes that diffi-

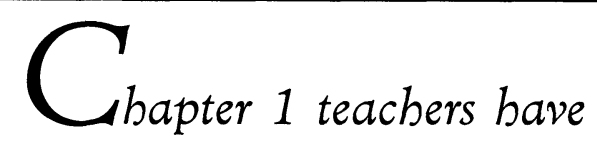

traditionally placed a beavy
emphasis on basic skills and

mastery learning.

culties in reading arise from complex combinations of psychological and educational factors that can be identified and remediated through careful testing and instruction. Next, the information-processing perspective, which is rooted in cognitive psychology, holds that reading problems are caused by processing difficulties, skill and strategy deficits, and limited motivation, while the social perspective focuses solely on the social context in which reading problems are manifested and defined. Lastly, the interactive perspective combines the information-processing and social ones to produce a view of reading problems that recognizes factors both internal and external to the reader.

Although these five perspectives may accurately reflect the trends in research on reading disability, they do not necessarily describe what teachers actually do in their classrooms. Therefore, a close examination was made of Chapter 1 teachers' curricular materials and their actual classroom practices in order to determine which of these perspectives, if any, were in fact represented.

This analysis led to three major changes in Wixson and Lipson's (1991) list. First, the medical perspective, which is not a viable orientation for most teachers because it discounts instruction, was combined with the psychoeducational perspective, which is quite prevalent in the field of special education but not in Chapter 1 classrooms. Together, aspects from these two perspectives depict a perceptual deficit orientation to reading problems, which, according to Howlett and Weintraub (1979), has been common among compensatory reading teachers.

Second, the information-processing perspective was divided into two instructional orientations that largely coincide with the practices of teaching basic and advanced skills, although it is important to stress that this link is conceptual and not chronological, for it is clear that skills-based practices predated information-processing research perspectives by several decades. 
Finally, the interactive perspective, which combines the information-processing and social perspectives, was deleted because it was not represented in any of the Chapter 1 practices or materials that were observed or examined. The social perspective, however, was retained because it is somewhat related to the philosophy of whole language, which is a part of some Chapter 1 programs.

Wixson and Lipson's (1991) five perspectives on research on reading problems were thus altered to include the following four theoretical orientations to compensatory reading instruction: perceptual deficit, skills, strategies, and social. The perceptual deficit orientation assumes that reading is a complex neurological process requiring the sophisticated integration of many elements, such as visual and auditory processing, and from this perspective, reading problems are thought to develop when there are deficits in these areas. The skills orientation, on the other hand, is based on the assumption that reading can be divided into a discrete set of skills, such as recognizing initial consonant blends and finding the main idea, and it implies that reading problems arise when such skills have not been mastered. Meanwhile, the strategies orientation considers reading to be the appropriate use of strategies, such as establishing a goal or purpose for reading, relating the text to past experiences, and continually asking whether or not it makes sense. From this perspective, reading problems are thought to be associated with a lack of such strategies or their inappropriate use. Finally, the social orientation defines reading as the construction of meaning through print in response to one's personal and social needs, and, based on this definition, reading problems are thought to develop when there is a discontinuity between the reader's needs and the context of the reading situation.

\section{The Survey}

\section{Subjects}

A survey was distributed to all the $\mathrm{K}-6$ Chapter 1 reading teachers in the state of Kentucky $(N=1,279)$, with a response rate of $82 \%(n=1,045)$. More than $95 \%$ of the respondents were female, and their teaching experience ranged from 0 to 48 years, with a mean of 18 . On the average, they had 8 years of experience as Chapter 1 reading teachers, and 9 years had passed since their last college courses in reading. In addition, $79 \%$ of the respondents had earned at least a master's degree.

\section{Source of Data}

The survey had three sections: beliefs, practices, and demographics (see Appendix). The beliefs section, which was similar to instruments created by DeFord (1985) and Duffy and Metheny (1979), consisted of 12 propositional statements to which the teachers responded on a 5-point scale ranging from strongly agree to strongly disagree. However, unlike these prior instruments, which measure classroom teachers' beliefs about reading in general, this section was designed specifically to reflect Chapter 1 teachers' beliefs about reading problems. Each of the four theoretical orientations was represented by three items, which were averaged to produce composite belief scores. For example, items 3, 5, and 8 represented the perceptual deficit orientation; items 4 , 7 , and 10 represented the skills orientation; items 6,9 , and 12 represented the strategies orientation; and items 1,2 , and 11 represented the social orientation.

The section of the survey dealing with practices consisted of four instructional vignettes that described plausible classroom scenarios, and the teachers again used a 5-point scale to indicate the extent to which these scenarios matched what they felt they did in their classrooms. Each vignette was consistent with one of the four theoretical orientations to reading problems. The first vignette represented the skills orientation; the second represented the perceptual deficit orientation; the third represented the strategies orientation; and the fourth represented the social orientation.

Both the 12 propositional statements and the 4 instructional vignettes were independently validated by a panel of seven experts, all with advanced degrees in reading and teaching experience. Each expert was presented with definitions for the four orientations and asked to label the 12 instructional beliefs items and the 4 instructional vignettes according to the orientation they felt each represented. The results indicated a very high level of agreement. On the instructional beliefs, the experts agreed more than $95 \%$ of the time, while on the instructional vignettes, their agreement was $100 \%$. These results suggest that the items on the survey were valid reflections of each orientation.

\section{Analysis of Data}

In order to explore the overall relationship between beliefs and practices, it was necessary to transform the quantitative variables into categorical ones. Therefore, the four composite belief scores for each teacher were compared so that the dominant perspective could be determined for each teacher. For example, if a teacher's composite belief score was strongest for the skills perspective, then her beliefs would be labeled "skills," whereas if it was strongest for strategies, then it would be labeled "strategies," and so on. The teachers' instructional practices were similarly determined based on their responses to the classroom vignettes. For example, if a teacher designated the skills vignette as the one most closely resembling her own self-reported classroom practices, then her instructional practices were labeled "skills," and so on.

After the beliefs and practices were thus determined, their overall relationship was explored through the construction of a contingency table, the performance of a chi-square test, and the calculation of Cramer's $V$. In order to determine which cells of the contingency table were responsible for the relationship, the standardized residuals of the observed and expected frequencies were analyzed in the manner de- 
scribed by Everitt (1977). Then, a comparison of professional characteristics was made among those teachers who had beliefs and practices that were consistent with the same perspective.

\section{Results}

When dominant beliefs were calculated, it was determined that almost three-fourths of the teachers had beliefs about reading problems that were consistent with one of the four orientations. In ascending order, the breakdown was as follows: $6.0 \%$ had social beliefs; $14.2 \%$ had perceptual deficit beliefs; $15.0 \%$ had skills beliefs; and $36.7 \%$ had strategies beliefs. The remaining $28.1 \%$ of the teachers could not be categorized under a single theoretical orientation, so they were labeled as having a combination of beliefs.

When dominant practices were calculated, it was determined that strategies practices were the most prevalent. In ascending order, $4 \%$ of the teachers matched their practices to the perceptual deficit vignette; $9 \%$ matched their practices to the skills vignette; $13.1 \%$ matched their practices to the social vignette; and $32.6 \%$ matched their practices to the strategies vignette. However, more than $40 \%$ of the teachers matched their instructional practices equally to two or more vignettes, which suggests that many teachers' practices were not driven by a single theoretical orientation. Like the teachers who had multiple beliefs, these teachers were labeled as implementing a combination of practices.

The chi-square test revealed that there was a relationship between the teachers' beliefs about reading instruction and their instructional practices, $\chi^{2}(16)=44.467, p=.0002$, but its magnitude was rather small (Cramer's $V=.103$ ). This result was due mainly to large numbers of teachers who did not have matching beliefs and practices. For example, most of the teachers with social beliefs reported a combination of practices, and more reported strategies practices than social ones. Similarly, of the teachers with skills beliefs, only $18 \%$ reported skills practices, while more than $30 \%$ reported strategies practices, and almost $37 \%$ reported a combination of practices. For the strategies beliefs, more than a third of the teachers reported matching practices, while approximately $40 \%$ reported a combination of practices. Finally, of the teachers with perceptual deficit beliefs, those who reported strategies practices outnumbered those who reported perceptual deficit practices at a ratio of five to one.

In spite of this relatively weak relationship between the teachers' beliefs and practices, an analysis of the adjusted residuals of the observed and expected frequencies presented in the contingency table revealed some definite trends. As can be seen in Table 1, the teachers who held social, skills, or strategies beliefs were more likely to engage

TABLE 1. Observed Frequencies, Expected Frequencies, and Adjusted Residuals of Teachers' Beliefs and Practices

\begin{tabular}{|c|c|c|c|c|c|c|}
\hline \multirow[b]{2}{*}{ Practices } & \multicolumn{5}{|c|}{ Beliefs } & \multirow{2}{*}{$\begin{array}{l}\text { Row } \\
\text { totals }\end{array}$} \\
\hline & 1 & 2 & 3 & 4 & 5 & \\
\hline \multirow[t]{3}{*}{ 1. Social } & 16 & 12 & 51 & 19 & 38 & 136 \\
\hline & 8.12 & 20.31 & 49.92 & 19.26 & 38.39 & \\
\hline & $3.059^{\star \star}$ & $-2.145^{\star}$ & 0.206 & -0.069 & -0.080 & \\
\hline \multirow[t]{3}{*}{ 2. Skills } & 3 & 28 & 21 & 15 & 26 & 93 \\
\hline & 5.55 & 13.89 & 34.14 & 13.17 & 26.25 & \\
\hline & -1.170 & $4.302^{* * \star}$ & $-2.963^{\star *}$ & 0.570 & -0.060 & \\
\hline \multirow[t]{3}{*}{ 3. Strategies } & 17 & 49 & 143 & 47 & 82 & 338 \\
\hline & 20.19 & 50.47 & 124.06 & 47.87 & 95.41 & \\
\hline & -0.892 & -0.273 & $2.603^{\star *}$ & -0.165 & $-1.973^{*}$ & \\
\hline \multirow[t]{3}{*}{ 4. Perceptual deficit } & 2 & 9 & 9 & 8 & 14 & 42 \\
\hline & 2.51 & 6.27 & 15.42 & 5.95 & 11.86 & \\
\hline & -0.339 & 1.207 & $-2.098^{\star}$ & 0.926 & 0.749 & \\
\hline \multirow[t]{3}{*}{ 5. Combination } & 24 & 57 & 157 & 58 & 133 & 429 \\
\hline & 25.62 & 64.06 & 157.47 & 60.75 & 121.1 & \\
\hline & -0.431 & -1.249 & -0.061 & -0.497 & 1.666 & \\
\hline Column totals & 62 & 155 & 381 & 147 & 293 & 1038 \\
\hline
\end{tabular}

${ }^{\star} p<.05 .{ }^{* \star} p<.01 .{ }^{* \star *} p<.001$. 
in practices consistent with their beliefs, while there was no apparent relationship for the perceptual deficit orientation. However, it should be noted that there were only eight teachers with matching perceptual deficit beliefs and practices. Other significant cells suggest that teachers who did not have dominant beliefs were less likely to implement strategies practices, while teachers with strategies beliefs were less likely to implement skills or perceptual deficit practices. In addition, there was a negative relationship between skills beliefs and social practices.

Table 2 presents a demographic analysis of the teachers in the cells with matching beliefs and practices. Although there were no substantial differences between this group of teachers and all the teachers surveyed, some definite trends were apparent among the four subgroups of teachers who had matching beliefs and practices. Almost three-fourths had beliefs and practices that were consistent with a strategies orientation to reading problems. These teachers, combined with the teachers with a social orientation, were generally more current in their professional training, more active in their professional reading, and more involved in professional organizations. For example, on the average, 13 years had passed since the skills and perceptual deficit teachers had taken their last college courses in reading, while for the strategies and social teachers only about 6 and 8 years had passed, respectively.

In addition, compared to the skills teachers, the strategies and social teachers more often reported that they frequently read professional journals and that they applied their reading to their instructional practices. In terms of specific journal titles, The Reading Teacher, The Journal of Reading, and Language Arts were all read more frequently by the strategies and social teachers, who were also more involved in professional organizations, such as inservices, workshops, and conferences. Finally, greater percentages of the strategies and social teachers belonged to professional groups such as the International Reading Association.

\section{Discussion}

Although Chapter 1 has traditionally been closely linked to the idea of basic skills instruction, this study indicates that such a connection is not apparent among Kentucky's Chapter 1 reading teachers. Most of those who were surveyed did not have beliefs that were consistent with a skills orientation to reading problems, and they did not engage exclusively in skills-based practices. Instead, to the extent that their beliefs

TABLE 2. Comparison of Training, Experience, and Professional Involvement Among Groups of Teachers Whose Beliefs Match Their Practices

\begin{tabular}{|c|c|c|c|c|}
\hline & $\begin{array}{l}\text { Perceptual } \\
\text { deficit }\end{array}$ & Skills & Strategies & Social \\
\hline $\begin{array}{l}\text { Mean years of teaching } \\
\text { experience }(S D)\end{array}$ & $14.6(4.4)$ & $21.0(7.1)$ & $16.7(9.2)$ & $18.1(13.0)$ \\
\hline $\begin{array}{l}\text { Mean years of Chapter } 1 \\
\text { teaching experience }(S D)\end{array}$ & $8.8(5.7)$ & $11.3(7.7)$ & $7.5(6.1)$ & $7.3(8.0)$ \\
\hline $\begin{array}{l}\text { Mean years since last } \\
\text { college course in reading }(S D)\end{array}$ & $13.5(7.0)$ & $12.5(7.1)$ & $8.3(6.4)$ & $5.7(7.4)$ \\
\hline Frequently read journals & $50.0 \%$ & $35.7 \%$ & $45.5 \%$ & $62.5 \%$ \\
\hline $\begin{array}{l}\text { Frequently apply journal } \\
\text { readings to instruction }\end{array}$ & $25.0 \%$ & $11.5 \%$ & $31.9 \%$ & $62.5 \%$ \\
\hline The Reading Teacher & $62.5 \%$ & $65.4 \%$ & $76.8 \%$ & $81.2 \%$ \\
\hline The Journal of Reading & $12.5 \%$ & $19.2 \%$ & $22.5 \%$ & $37.5 \%$ \\
\hline Language Arts & $12.5 \%$ & $3.8 \%$ & $18.1 \%$ & $43.8 \%$ \\
\hline $\begin{array}{l}\text { Frequently participate } \\
\text { in professional organizations }\end{array}$ & $37.5 \%$ & $50.0 \%$ & $57.0 \%$ & $87.5 \%$ \\
\hline International Reading Association & $14.3 \%$ & $15.4 \%$ & $45.1 \%$ & $46.7 \%$ \\
\hline Kentucky Reading Association & $0 \%$ & $11.5 \%$ & $24.1 \%$ & $20.0 \%$ \\
\hline Count & 8 & 28 & 143 & 16 \\
\hline Percentage & 4.1 & 14.4 & 73.3 & 8.2 \\
\hline
\end{tabular}


and practices were consistent with theoretical orientations to reading problems, the strategies orientation was dominant, as almost three-fourths of the teachers with matching beliefs and practices fell into this category.

However, it is important to stress that most of the teachers did not have matching beliefs and practices and that more than two-thirds of those surveyed reported beliefs and practices that were not consistent with a strategies orientation to reading problems. Nearly $30 \%$ had mixed or combined beliefs, while more than $40 \%$ reported multiple practices. In addition, many teachers possessed beliefs that were inconsistent with their reported practices, so that although there was a general connection between their beliefs and practices, the overall relationship was not a strong one. As suggested by Barr and Duffy (1978), many teachers may not possess singular beliefs about reading, and there may well be a host of contextual factors that mediate the relationship between beliefs and practices, including board-mandated curricula, classroom management concerns, and instructional expectations by students, parents, and administrators. Unfortunately, the survey methodology employed in this study is not well suited to exploring these kinds of contextual factors.

In spite of the rather weak overall relationship between beliefs and practices, the analysis of the teachers with matching beliefs and practices suggests that if policymakers and administrators want Chapter 1 teachers to address advanced skills in their practices, then they must consider the teachers' prior beliefs about reading problems. Teachers with skills, perceptual deficit, or mixed beliefs were less likely to link their practices to a strategies orientation to reading problems, while the strategies and social teachers tended to report greater professional involvement. On the average, these teachers had more recently taken a college course in reading; they were more active in their reading of journals; and they participated more often in professional organizations. Consequently, this study suggests that Chapter 1 teachers who are more professionally involved are more likely to possess beliefs and engage in practices that are consistent with a strategies, or advanced skills, orientation to reading problems.

However, fostering extracurricular professional involvement among teachers is not a simple task. Factors such as heavy class loads, noninstructional duties, and burdensome paperwork often leave them with little or no time to read journals, interact with their colleagues, or attend conferences-even if such opportunities were readily available. Therefore, there are several things that principals and administrators can do to encourage Chapter 1 teachers' professional development. First, when they design schedules and assign duties, they can set aside regular periods of time for groups of teachers to meet and share instructional ideas from their classrooms. These groups could include Chapter 1 teachers and aides as well as classroom teachers, and such an arrangement would involve no additional expenditures of money, only a bit more planning. Next, principals can help teachers to establish resource centers stocked with professional books and journals-and possibly even instructional materials, both teacher made and commercial. These centers, which could be set up in the existing school libraries, would provide teachers with additional access to new ideas and enable them to keep informed about new developments in educational research. Teachers could also be periodically provided with release time in order to make it easier for them to attend conferences and other professional meetings that occur while school is in session. Finally, school districts can set up tuition reimbursement funds to encourage teachers to continue their educations by enrolling in college courses and professional development workshops.

These recommendations would foster an atmosphere that is conducive to the professional development of Chapter 1 teachers, which would ultimately have the potential to enhance both the teaching and the learning that occurs in Chapter 1 classrooms.

JAMES A. MUCHMORE is a doctoral student in the Reading and Literacy Program at the University of Michigan. His research focuses on issues in literacy, teacher thinking, and teacher development. Address: James A. Muchmore, 1228 School of Education Building, The University of Michigan, Ann Arbor, MI 48109-1259.

\section{REFERENCES}

Advanced Technology. (1990). Thinking about reading about thinking about reading about thinking: Advanced skills in Chapter 1: Workshop: Leader's guide. Indianapolis: Author.

Barr, R., \& Duffy, G. (1978, March). Teacher conceptions of reading: The evolution of a research study. Paper presented at the annual meeting of the American Educational Research Association, Toronto.

Calfee, R. (1986, June). Curriculum and instruction: Reading. Paper presented at the Conference on the Effects of Alternative Designs in Compensatory Education, Washington, DC.

Clark, C. M., \& Peterson, P. L. (1986). Teachers' thought processes. In M. C. Wittrock (Ed.), Handbook of research on teaching (pp. 255-296). New York: Macmillan.

DeFord, D. (1985). Validating the construct of theoretical orientation in reading instruction. Reading Research Quarterly, 20, 351-367.

Duffy, G. G., \& Metheny, W. (1979). Measuring teachers' beliefs about reading. Research Series No. 41. East Lansing: Michigan State University, Institute for Research on Teaching.

Everitt, B. S. (1977). The analysis of contingency tables. London: Chapman \& Hall.

Hollingsworth, S. (1989). Prior beliefs and cognitive changes in learning to teach. American Educational Research Journal, 26, $160-190$

Howlett, N., \& Weintraub, S. (1979). Instructional procedures. In R.C. Calfee \& R.A. Drum (Eds.), Teaching reading in compensatory classes (pp. 87-103). Newark, DE: International Reading Association.

Johnson, K. E. (1992). The relationship between teachers' beliefs and practices during literacy instruction for non-native speakers of English. Journal of Reading Behavior, 24, 83-108.

Kinzer, C. K., \& Carrick, D. A. (1986). Teacher beliefs as instructional influences. In J. A. Niles \& R. V. Lalik (Eds.), Solving problems in literacy: Learners, teachers and researchers. Thirty-fifth yearbook of the National Reading Conference (pp. 127-134). Rochester, NY: The National Reading Conference.

Knapp, M. S., Shields, P. M., \& Turnbull, B. J. (1992). Academic challenge for the children of poverty: Study of academic instruction 
for disadvantaged students (Summary report). Washington, DC: U.S. Department of Education, Office of Policy and Planning. (ERIC Document Reproduction Service No. ED 353 355)

Knapp, M. S., Turnbull, B. J., \& Shields, P. M. (1986). New directions for educating the children of poverty. Educational Leadership, 48(1), 4-8.

Munby, H. (1984). A qualitative study of teachers' beliefs and principles. Journal of Research in Science Teaching, 21, 27-38.

Richardson, V. (1990). Significant and worthwhile change in teaching practice. Educational Researcher, 19(7), 10-18.

Richardson, V., Anders, P., Tidwell, D., \& Lloyd, C. (1991). The relationship between teachers' beliefs and practices in reading comprehension instruction. American Educational Research Journal, $28,559-586$

Romberg, T. A. (1986, June). Mathematics for compensatory school programs. Paper presented at the Conference on the Effects of Alternative Designs in Compensatory Education, Washington, DC.
Rupley, W. H., \& Logan, J. W. (1986). Relationship between teachers' beliefs about reading and their reported use of questioning and engagement strategies. In J. A. Niles \& R. V. Lalik (Eds.), Solving problems in literacy: Learners, teachers and researchers. Thirty-fifth yearbook of the National Reading Conference (pp. 165-170). Rochester, NY: The National Reading Conference.

U.S. Department of Education. (1990). Chapter 1 policy manual. Washington, DC: Author.

U.S. Department of Education. (1992). National assessment of the Chapter 1 program: The interim report. Washington, DC: Author.

Wixson, K. K., \& Lipson, M. Y. (1991). Perspectives on reading disability research. In R. Barr, M. L. Kamil, P. B. Mosenthal, \& P. D. Pearson (Eds.), Handbook of reading research (pp. 539-570). New York: Longman.

Zumwalt, K. K. (1986, June). Curriculum and instruction: Reactions. Paper presented at the Conference on the Effects of Alternative Designs in Compensatory Education, Washington, DC.

\section{Appendix}

\section{Reading Survey}

A. Read each of the following statements and circle the number that best describes your feelings about reading problems and/or reading instruction.

1. Materials for students with reading problems should be written in natural language without an emphasis on short and simple words and sentences.

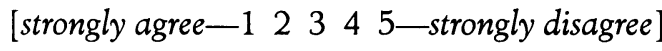

2. If a child says the word "home" instead of "house," the substitution should not be corrected.

[strongly agree-1 $22 \quad 3 \quad 4$ 5-strongly disagree]

3. Children with reading problems should be taught to compensate for weaknesses in perceptual, discrimination, memory, and motor skills. [strongly agree - $122 \quad 3 \quad 4$ 5-strongly disagree]

4. The process of reading can be divided into a definite sequence of subskills.

[strongly agree-1 12034 5-strongly disagree]

5. Activities that build hand-eye coordination are useful in helping children with reading problems.

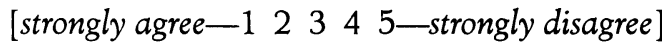

6. Before reading a new book, children should be taught to think about what they already know about the type of text, the topic, and the author's purpose.

[strongly agree-1 12034 5-strongly disagree]

7. When a student is having reading difficulties, it is important to administer a reading skills test in order to determine which skills to teach.

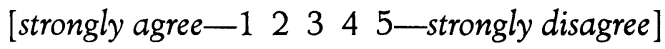

8. Presenting children with visual and/or auditory discrimination tasks is an effective way to address their reading problems.

[strongly agree-1 12304 5-strongly disagree]

9. When reading an unfamiliar text, children should be taught to ask themselves questions such as, "Does this make sense?"

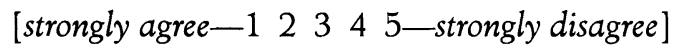

10. Reading problems are best addressed through the direct instruction of those basic skills in which the students are lacking.

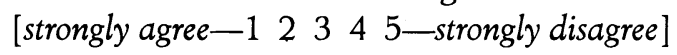

11. A child can begin to read without knowing all the letters of the alphabet.

[strongly agree-1 $22 \quad 3 \quad 4$ 5-strongly disagree]

12. It is important for teachers to model how good readers choose appropriate strategies when reading an unfamiliar text.

[strongly agree-1 $\begin{array}{lllll}2 & 3 & 4 & 5 \text {-strongly disagree] }\end{array}$

B. Carefully read each of the following scenarios and indicate the extent to which they describe what you currently do in your classroom.

1. The remedial objectives for the students in your classroom have been determined by diagnosticprescriptive procedures, and each student receives an individualized instructional program. For example, when Julie comes to your classroom, she looks in her folder and sees that she is to work on a lesson/module on the main idea during this session. You observe her as she works, provide guidance when she asks questions or appears to 
need assistance, and check her work when she has finished. When she has completed this set of lessons or activities successfully, you consult her record to determine which skill(s) she should work on next and make the appropriate assignment.

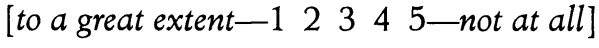

2. You have carefully studied all available test data to identify the specific auditory and/or visualperceptual deficits that may be interfering with your students' learning to read. Because Cindy has poor eye-hand coordination, she strings beads and laces cards to strengthen this area of weakness. Gary's problem is auditory discrimination and auditory memory, so he is working with a set of materials that gradually increases the requirements for following orally administered directions. As your students improve in their psychomotor abilities, you gradually introduce more cognitive tasks associated with reading, such as sound blending.

[to a great extent-1 23345 -not at all]

3. You have noticed in your weekly anecdotal assessments that John does not monitor his comprehension or employ fix-up strategies as he reads. To address this problem, John is participating in group reading-strategy lessons. Each student in the group has a copy of the text for the day, and the lesson begins with a discussion of what the day's text is most likely to be about. You then explain how to use a particular strategy and the importance of doing so, and ask the students to try the strategy as they read a section of the text. You continue to guide, discuss, and practice the use of the strategy as you make your way through the text. When you determine that the students understand how to use the strategy, you provide them with activities that permit you to evaluate their ability to apply the strategy independently, and determine their readiness to move ahead.

[to a great extent-1 223445 -not at all]

4. Children in your program choose from an array of library books for their reading practice. For example, Joe is interested in baseball and has chosen to read a book about Johnny Bench. When he comes to your class, you direct him to sit quietly and read his book to himself. When he has finished reading, you ask him to write about what he has just read in the journal he keeps in your room. When he asks you how to spell a word, you suggest that he write what he hears. When he is finished writing in his journal, you discuss with him how he liked the materials and why, and ask him to tell you about different aspects of the text. As a concluding activity, you may ask him to produce an artistic representation of the book, such as a diorama or a radio play. When you feel he has explored the text to his satisfaction, the process begins again with another selection. [to a great extent-1 203445 -not at all]

C. Please describe yourself by responding to the following questions.

1. Gender? Male ___ Female

2. What is the highest degree you have received? Bachelor's __ Specialist's __ Master's Doctoral

3. How many years have you taught in Chapter 1 ? years

4. How many total years of teaching experience do you have? years

5. How many years ago did you complete your most recent college class focusing on reading instruction? _ years

6. How often do you participate in professional organizations? (e.g., workshops, meetings, conventions, etc.) Frequently Seldom Never Occasionally

7. How often do you read professional journals? Frequently Seldom Occasionally

8. Which of the following professional journals do you currently read?

__ Journal of Reading Reading Teacher

__ Reading Research Quarterly Language Arts Other __ None

9. How often do you apply what you read in professional journals to your classroom practice? Frequently Seldom Occasionally Never

10. Which of the following nonunion professional organizations are you currently a member of? Association for Supervision and Curriculum Development (ASCD) International Reading Association (IRA) Kentucky Reading Association (KRA)

_ National Council for Teachers of English (NCTE) Orton Society Other None 